\title{
Múltiplos olhares e perspectivas na linguagem e cognição
}

\author{
Sabrine Amaral Martins TOWNSEND (1) \\ Universidade de Santa Cruz do Sul (UNISC)
}

\section{RESUMO}

Os professores Heronides Moura, Rosângela Gabriel e Paulo Roberto Gonçalves-Segundo debatem teórica e praticamente seus projetos de pesquisa acerca da linguagem e da cognição. De forma concisa, os pesquisadores apresentam dados importantes sobre: 1) sentenças metafóricas sobre corrupção em corpus de jornal, 2) efeitos da aprendizagem da leitura na memória e na percepção e, 3) análises de espaços conceptuais em trechos de discursos de parlamentares a favor da intervenção militar. A partir das três exposições, é possível concluir que o processo que subjaz essas pesquisas sobre cognição é a necessidade de uma leitura crítica da realidade. A compreensão dos fenômenos descritos (ou a falta dela) implica significativamente na legitimação de discursos repudiados pelas instituições e associ-

OPEN ACCESS

EDITADO POR Raquel Freitag

AVALIADO POR Heronides Moura

DATAS Recebido: 01/06/2020 Aceito: $27 / 06 / 2020$ Publicado: 26/08/2020

COMO CITAR Townsend, S. A. M. (2020). Múltiplos olhares e perspectivas na linguagem e cognição. Revista da Abralin, v. 19, n. 2 , p. 1-5, 2020. ações científicas, como os discursos de ódio e de impunidade. Além disso, os benefícios advindos da aprendizagem de uma leitura crítica reforçam que a base de uma sociedade justa se alicerça na perspectiva de uma educação de qualidade e na democracia.

\section{ABSTRACT}

Professors Heronides Moura, Rosângela Gabriel and Paulo Roberto Gonçalves-Segundo debate theoretically and practically their research projects on language and cognition. In summary, the researchers present important data on: 1) metaphorical sentences about corruption in a newspaper corpus, 2) effects of learning to read on memory and perception, and 3) analysis of conceptual spaces in excerpts of speeches by parliamentarians in favor of military intervention. From the three expositions, it is possible to conclude that the process that underlies these researches on cognition is the need for a critical reading of reality. The understanding of the 


\section{REVISTA DA ABRALIN}

described phenomena (or the lack of it) significantly implies the legitimation of discourses repudiated by scientific institutions and associations, such as hate and impunity ones. In addition, the benefits of learning to read critically reinforce that the basis of a fair society is based on the quality of education and democracy.

PALAVRAS-CHAVE

Cognição. Leituras. Perspectivas.

KEYWORDS

Cognition. Reading. Perspectives.

A mesa-redonda de 25 de maio de 2020, disponibilizada ao vivo na série de conferências on-line organizadas pela Associação Brasileira de Linguística (ABRALIN) durante a pandemia de coronavírus (COVID-19), oportunizou múltiplos olhares sobre a linguagem e a cognição. As visões da professora Dra. Rosângela Gabriel (UNISC), do professor Dr. Paulo Roberto Gonçalves-Segundo (USP) e do professor Dr. Heronides Moura (UFSC), que também foi mediador da mesa, ampliaram o escopo relativo ao papel dos recursos linguísticos para uma leitura crítica da sociedade. Sob o título Linguagem e cognição: olhares e perspectivas, os pesquisadores abordaram de forma clara e coerente as teorias que estudam e as pesquisas que desenvolvem em suas instituições e realizaram uma importante reflexão acerca das contribuições da linguística de ótica cognitivista para resistir ao cenário brasileiro atual. Cada professor destacou, à luz de suas investigações, as perspectivas diante de: 1) percepção de metáforas sobre corrupção, 2) benefícios da percepção e memória advindos da aprendizagem da leitura e 3) análise crítica de discursos pró intervenção de militares. Ainda que advindos de diferentes contextos, a exposição dos professores funde-se na luta pela ciência, pela educação, pela pesquisa e pela democracia.

O debate inicia com o tema Corrupção sem fim: tempo e aspecto em metáforas sobre corrupção no Brasil, com o professor Dr. Heronides Moura (UFSC). O professor apresenta metáforas sobre corrupção, extraídos de um corpus de 140 ocorrências de sentenças metafóricas, extraídas do Jornal Folha de São Paulo no período de 2012 a 2017. Heronides destaca a riqueza e a complexidade do assunto, definindo metáfora como uma troca de contextos (RICHARDS, 1936). Ao analisar o jornal, o pesquisador depara-se com os inúmeros usos do termo 'corrupção', mais distantes semanticamente do sentido literal. Mesmo que a definição jurídica seja de crime que envolva a utilização de dinheiro público para objetivos de lucro privado, observa-se uso metaforizado da corrupção como se tratasse de: 1) doença, vírus; 2) força destrutiva incontrolável que destrói o país; 3) sujeira; 4) trama inabalável que se espalha; 5) pessoa com amigos poderosos; 6) mecanismo/engrenagem e, até mesmo, 7) farra. Portanto, a metáfora da corrupção parece constituir-se de um enorme poder avassalador, cuja 


\section{REVISTA DA ABRALIN}

origem e destino não são bem estabelecidos (MOURA; LOPES, 2020). 87\% das proposições pesquisadas (123/141) apresentam-se no aspecto imperfectivo, atribuindo-se, então, a esse aspecto verbal uma particularidade de eternidade, sem tempo e espaços definidos. A ideia de falta de finitude é evocada pelo uso corrente do presente do indicativo (61 casos), do pretérito imperfeito (12), do pretérito perfeito composto (1), das construções progressivas (gerúndio) (8), das perífrases iterativas e habituais (13), das construções de particípio (14), do futuro do presente (6), do imperativo (8) e do infinitivo (10) nas afirmações. O aspecto imperfectivo coloca-se tão profundamente impregnado na percepção do conceito de corrupção que discutir o tema pode ser um sinal de uma conformidade de que não há esperança para seu fim entre os participantes de uma conversa

A segunda exposição é realizada pela professora Dra. Rosângela Gabriel (UNISC). Rosângela capta a audiência com a polissemia do termo vírus, na fala 'Em tempos de Covid-19, que tal falarmos sobre o 'vírus' da leitura?', dada a definição de Frith (1998) de aprendizagem de leitura como um vírus do bem. Posto que a leitura é essencial, ainda mais em tempos de pandemia, a pesquisadora destaca que aprender a ler pode transformar o cérebro, trazendo benefícios para os indivíduos como melhorias na percepção, na memória e na atenção. A percepção é definida por Lent (2010, p. 557), como "a capacidade de associar informações sensoriais à memória e cognição". Já a memória é definida via modelos de Baddeley (2000) e de Cowan (2008). Tanto a percepção quanto a memória atuam na nossa relação com o mundo externo, que é sensorial e se transforma pela construção de um conjunto de memórias e de informações. A partir do primeiro contato, a percepção do mundo externo passa a ser mediada por conhecimentos novos e armazenados, deixando de ser uma relação direta entre mundo e indivíduo. Sendo a percepção e a memória tão intimamente interligadas, a aprendizagem da leitura não poderia ocorrer de modo distinto. O vírus do bem do conhecimento alfabético, por assim dizer, permite perceber, reiterar e organizar as vivências, evidenciando a direcionalidade da leitura conforme cada cultura. O sistema cognitivo é moldado para aprender a ver as informações relevantes e ignorar as que não são importantes, aprender a ouvir e aprender a ouvir com os olhos automatizar o processamento de tal forma que toda a atenção do sistema possa ser direcionada para a aprendizagem - fenômeno observado nos testes de Stroop (STROOP, 1935). E tudo isso acontece quando lemos. Esses preceitos embasam o projeto da pesquisadora, que compara crianças em fase de alfabetização e adultos com oportunidades de alfabetização tardia, tanto brasileiros quanto belgas. Os resultados iniciais dos trabalhos advindos do projeto indicam o impacto do aprendizado da leitura na memória, em especial na memória de ordem (em oposição à memória de itens) (GABRIEL et al., 2019) e conclui que escolaridade e aprendizagem da leitura são difíceis de separar, pois ambas alteram o modo como olhamos o mundo. E ainda importante, esses dados corroboram com a imprescindibilidade da leitura como um contágio positivo, que deve ser acessível a todos e propiciar benefícios a todas faixas etárias e classes sociais. A leitura, concebida dessa maneira, permite que haja múltiplos olhares e perspectivas diante de uma dada realidade.

A terceira e última fala é feita pelo professor Dr. Paulo Roberto Gonçalves-Segundo (USP), intitulada A construção de espaços conceptuais na legitimação discursiva e na mobilização social: articulações entre linguagem e cognição. Paulo assegura uma articulação entre o compromisso 


\section{REVISTA DA ABRALIN}

sociossemiótico e a linguística cognitiva através da análise discursiva dos espaços conceituais dos seguintes textos: 1) tweet do filho do presidente da República; 2) entrevista com o ex-deputado e cantor sertanejo Sérgio Reis 3) discurso do presidente em uma manifestação pró-intervenção militar. Conforme Paulo, a maneira como se constrói um discurso funcionará como ponto de partida para o público organizar a realidade conceitual invocada de modo particular relativo a essa visão. Por isso, é apresentada a noção de perspectivação como um processo cognitivo experienciado no domínio visual, por conta da nossa situacionalidade física, não restrito à espacialidade (FILARDOLLAMAS, HART; KAAL 2018). Segundo o pesquisador, o fenômeno da perspectivação ocorre conosco quando há empatia com opiniões alternativas às nossas ou as ponderamos, e, assim, a perspectivação permite distinções significativas, em domínios semânticos mais abstratos, como no tempo e em uma modalidade. Essa nova capacidade de perspectivar permite: 1) a localização dos movimentos e entidades no nosso espaço; 2) a aproximação e o afastamento temporal dos eventos, comprimindo ou expandindo tal referência; 3) a assumpção de determinados posicionamentos como corretos ou errados, e, por fim, 4) geração de efeitos empáticos ou antagônicos, ativação de afetos, mobilização de ações ou, ainda, a legitimação de concepções ou iniciativas, como ocorre no corpus analisado. Nos três textos abordados pela pesquisa, há um posicionamento e uma movimentação conceptual em direção à polarização política, principalmente na argumentação pró legitimação de uma intervenção militar. No primeiro caso, um tweet de um dos filhos do presidente, Carlos Bolsonaro, há uma trajetória linguística de defesa do capitalismo liberal em oposição ao socialismo. O enunciador utiliza recursos linguísticos para fazer a alusão de presente e de realidade (com o uso do imperfectivo!), utiliza a ideia de transformação como destino da jornada (através de metáfora conceitual) e salvaguarda uma força motriz esquerdista que se opõe ao contexto idealizado (movimentação axiológica e marcas dêiticas do texto). Na fala de Carlos, ocorre o fenômeno da proximização, de Piotr Cap (2013), em que o exogrupo aproxima-se do endogrupo para legitimar uma intervenção, tal qual ocorre na entrevista de Sérgio Reis. Para o pesquisador, o discurso do ex-deputado e sertanejo idealiza o povo como um endogrupo, com um poder suficiente para requerer uma intervenção militar no país. Já quando Sérgio Reis se refere à esquerda, evidencia-se a opinião de que essa perspectiva ideológica não é popular e, sim, algo sobrenatural, que assola os indivíduos, como um vírus maligno. Na terceira análise, o discurso de Jair Bolsonaro no dia 19/04/20, assume-se um posicionamento e um movimento conceptual da velha política (patifaria) para a nova política (soberania popular). Uma série de recursos e estratégias linguísticas são utilizados para discorrer sobre uma instabilidade esperançosa, repercutindo em um enquadramento negativo para o contexto atual. Todas essas ideias vêm ao plano enunciativo para ilustrar, com o auxílio de recursos e estratégias linguísticas de luxo, uma proposta falsa de legitimação e de intervenção militar preconizada pelo povo, diante da inaceitabilidade da situação presente.

As exposições dos professores Heronides, Rosângela e Paulo Roberto contribuem com diferentes olhares e perspectivas sobre a linguagem e a cognição. Todas as falas possuem em comum a necessidade urgente de uma compreensão e de uma leitura crítica do contexto brasileiro atual. Como se fosse um contágio positivo, deseja-se que a capacidade de ler o mundo se espalhe e não 


\section{REVISTA DA ABRALIN}

repercuta na legitimação de discursos de ódio e de impunidade eterna, como explanado pela primeira e última falas, respectivamente. O novo olhar e a nova perspectiva política emergem dos discursos presentes nas redes, emaranhando os indivíduos - futuros eleitores - em uma teia de argumentos favoráveis à intervenção militar, por exemplo, ameaçando gravemente o regime democrático. Somente com múltiplos olhares e perspectivas, em particular, propiciados pelo saber científico, é que seremos uma sociedade crítica. É a partir da(s) leitura(s) e do acesso democrático à educação é que poderemos aprimorar nossa percepção e construir uma realidade, de fato, transformadora. Como um vírus do bem, desviando da perspectiva difusa que abala os alicerces de uma sociedade justa, que o olhar crítico propiciado pelas análises linguísticas aqui expostas se una na luta pela ciência, pela pesquisa, pela educação e pela democracia em tempos tão difíceis.

\section{REFERÊNCIAS}

BADDELEY, Alan. The episodic buffer: a new component of working memory? Trends Cognitive Sciences, n. 4, p. 417-423. 2000. DOI: https://doi.org/10.1016/s1364-6613(00)01538-2

CAP, Piotr. Proximization. The Pragmatics of Symbolic Distance Crossing. Amsterdam - Philadelphia: John, 2013.

COWAN, Nelson. What are the differences between long-term, short-term, and working memory? Progress in brain research, v. 169, p. 323-338, 2008.

FILARDO-LLAMAS, Laura; HART, Christopher; KAAL, Bertie. Space, time and evaluation in ideological discourse. $1^{\mathrm{a}}$. ed. New York: Routlegde, 2018.

FRITH, Utah. Literally changing the brain. Brain, n. 121, v. 6, p. 1011-1012, June 1998. DOI: https://doi.org/10.1093/brain/121.6.1011

GABRIEL, Rosângela; KOLINSKY, Régine.; GREGORY, Marilane. M.; CARVALHO, Kadine S.; MORAIS, José. J. The disadvantages of adult illiteracy in verbal memory tasks. In: Society for the Scientific Study of Reading (SSSR), 2019. Twenty-sixth Annual Meeting, 2019 .

LINGUAGEM e cognição: olhares e perspectivas. Mesa-redonda apresentada por Heronides Moura, Rosângela Gabriel e Paulo Roberto Gonçalves-Segundo [s.l., s.n], 2020. 1 vídeo (2h 49 min 46s). Publicado pelo canal da Associação Brasileira de Linguística. Disponível em: https://www.youtube.com/watch?v=satHgimJ7z0\&t=7650s. Acesso em: 21 ago 2020.

MOURA, Heronides; LOPES, Fábio da S. O vírus nos ronda: metáforas sobre vírus e sobre corrupção. O que produz o PPGL - Programa de Pós-Graduação em Linguística da UFSC. p. 1-28, 2020. Disponível em: https://ppglin.posgrad.ufsc.br/2020/05/13/ovirus-nos-ronda/. Acesso em: 01 jul 2020.

LENT, Roberto. Cem bilhões de neurônios. Rio de Janeiro: Atheneu, 2004.

RICHARDS, Ivor Armstrong. The Philosophy of Rhetoric. Oxford: Oxford University Press, 1936.

STROOP, Ridley. Studies of interference in serial verbal reactions. Journal of Experimental Psychology, v. 18, p. 643-662, 1935. 